\title{
As Aminas Aromáticas no Contexto da Carcinogénese Química
}

\section{Resumo}

Os estudos efectuados em animais, incluindo os seres humanos, têm salientado a importância de alguns factores na etiologia de uma grande variedade de cancros. Entre eles, destacam-se os factores ambientais como as radiações ionizantes e ultra-violeta e a exposição a certas classes de compostos, associados, ou não, a um efeito sinérgico entre estes e a predisposição genética de certos indivíduos.

Embora o reconhecimento do potencial genotóxico das aminas aromáticas date do século XIX, foi somente a partir da segunda metade do século $X X$ que a comunidade científica conseguiu demonstrar, de forma inequivoca, a sua acção mutagénica e carcinogénica no homem e em algumas espécies animais. Apesar de, in vivo, a formação de adutos covalentes com o ADN ser um acontecimento dependente de factores como o grau de exposição, tipo de composto, fenótipo dos indivíduos, entre outros, a sua capacidade de induzir alterações permanentes e hereditárias no conteúdo genético celular está largamente comprovada.

Neste artigo, far-se-à referência às consequências biológicas resultantes da exposição exógena dos seres humanos às aminas aromáticas. Contudo, os princípios e os mecanismos descritos são, de um modo geral, extensíveis a outras classes de compostos orgânicos genotóxicos. Serão ainda abordados, de uma forma sucinta, os principais percursos subjacentes à sua activação metabólica, a formação de adutos covalentes e o tipo de lesões/mutações induzidas no ADN.

\section{Introdução}

Os resultados experimentais acumulados ao longo das últimas décadas têm demonstrado que os efeitos biológicos de certas classes de compostos estão intimamente relacionados com a formação de adutos covalentes*. As características estruturais destes adutos, e em especial o tipo de perturbações conformacionais que a sua presença pode provocar na estrutura tridimensional da dupla hélice do ADN, são factores considerados determinantes no tipo de mutações por eles produzido. Muito embora a activação de sequências de ADN específicas (designadas proto-oncogenes) como resultado da exposição in vivo a agentes químicos cancerígenos tenha sido estabelecida, as razões associadas a esta activação preferencial permanecem obscuras.

Os trabalhos pioneiros de Elizabeth e James Miller, na área da carcinogénese química, vieram dar um contributo significativo para o reconhecimento da importância da activação metabólica na formação de adutos covalentes envolvendo ácidos nucleicos e proteínas ${ }^{1}$. Em testes realizados em roedores com algumas aminas aromáticas, aqueles autores observaram que a indução de tumores era um acontecimento independente do local de aplicação/administração do cancerígeno, facto que veio dar consistência à hipótese de certas classes de compostos necessitarem ser previamente activadas a metabolitos mais reactivos. 0 2-aminonaftaleno (1a) (fig.1), por exemplo, que induz cancros na bexiga de cães revelou ser totalmente inócuo quando implantado cirurgicamente no epitélio da bexiga? ${ }^{2}$

A maioria dos compostos orgânicos genotóxicos são activados metabolicamente a espécies reactivas com caracteristicas electrófilas, vulgarmente designadas por "espécies cancerígenas finais". Admite-se, assim, que uma das primeiras etapas da iniciação de um processo cancerígeno esteja associada à reacção de uma espécie electrófila, directa ou

\footnotetext{
1 Instituto Superior de Ciências da Saúde - Sul, Campus Universitário - Quinta da Granja, 2825-511 Caparica.

2 Departamento de Química, Centro de Química Fina e Biotecnologia, Faculdade de Ciências e Tecnologia, UNL, 2829-516 - Caparica (luisa.lima@dq.fct.unl.pt).

* Aduto é, no sentido lato da designação, uma entidade molecular resultante da formação de uma ligação covalente entre uma espécie electrófila e um dos centros nucleófilos presentes nas macromoléculas biológicas (ADN, ARN, etc.).
} 
formada por activação metabólica, com - ADN/ARN. Sabe-se, actualmente, que nesta activação metabólica estão envolvidas quase todas as enzimas implicadas na metabolização de xenobióticos ${ }^{3}$. Têm sido propostos vários modelos ou vias de activação metabólica promovida pelo sistema enzimático dependente do citocromo $\mathrm{P}_{450}$, localizado na fracção microssomal do retículo endoplasmático. A maioria das etapas envolvidas neste processo de activação são reacções de oxidação e podem ser catalisadas por desidrogenases, mono-oxigenases e peroxidases ${ }^{4,5}$.

\section{Reconhecimento das aminas aromáticas como cancerígenos químicos}

A indução de tumores a partir desta classe de compostos foi originalmente atribuída à actividade profissional por Ludwig Rehn', em 1895, ao observar um índice elevado de cancros da bexiga em trabalhadores da indústria de corantes derivados da anilina (2a) (fig.1). Verificou-se, mais tarde, que a indução de tumores naquele orgão era devida ao 2 -aminonaftaleno (1a), um contaminante presente naqueles corantes. Outros autores, relacionaram também o aumento da incidência deste tipo de cancro, em trabalhadores de fábricas de corantes e borracha, com a exposição crónica a aminas poliaromáticas como o 4-aminobifenilo (3a) e a benzidina (4,4'-diaminobifenilo, (3b) $)^{7}$ (fig. 1).

A confirmação inequívoca dos danos provocados por estes compostos surgiu na década de 30 , após se ter verificado, em experiências realizadas com cães e macacos, que estes contraíam doenças do foro oncológico depois de terem sido submetidos a doses elevadas de 2-aminonaftaleno (1a) (fig. 1). na sua dieta 8 .

Uma vez que a utilização deste tipo de compostos tem vindo a ser drasticamente reduzida na indústria, o fumo do tabaco passou a ser, actualmente, uma das principais fontes de exposição do<smiles>[R]c1c(N)ccc2ccccc12</smiles><smiles>[R]C1=CC=C(C2=CC=C(N)C([R7])C2)C([R2])C1</smiles>

3a $\left(\mathrm{R}_{1}=\mathrm{R}_{2}=\mathrm{R}_{3}=\mathrm{H}\right)$ $3 b\left(\mathrm{R}_{1}=\mathrm{R}_{2}=\mathrm{H} ; \mathrm{R}_{3}=\mathrm{NH}_{2}\right)$<smiles>[R]N([R])c1ccc2ccccc2c1</smiles>

2a $\quad\left(\mathrm{R}_{1}=\mathrm{R}_{2}=\mathrm{R}_{3}=\mathrm{H}\right)$

$2 \mathrm{~b}\left(\mathrm{R}_{1}=\mathrm{H}=\mathrm{R}_{2}=\mathrm{H}, \mathrm{R}_{3}=2-\mathrm{Me}\right)$

2c $\left(\mathrm{R}_{1}=\mathrm{H}=\mathrm{R}_{2}=\mathrm{H}, \mathrm{R}_{3}=3-\mathrm{Me}\right)$

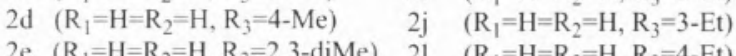

$\left(\mathrm{R}_{1}=\mathrm{H}=\mathrm{R}_{2}=\mathrm{H}, \mathrm{R}_{3}=2,3\right.$-diMe $) \quad 2 \mathrm{l} \quad\left(\mathrm{R}_{1}=\mathrm{H}=\mathrm{R}_{2}=\mathrm{H}, \mathrm{R}_{3}=4\right.$-Et $)$

$2 \mathrm{f} \quad\left(\mathrm{R}_{1}=\mathrm{H}=\mathrm{R}_{2}=\mathrm{H}, \mathrm{R}_{3}=2,4-\mathrm{diMe}\right) \quad 2 \mathrm{~m} \quad\left(\mathrm{R}_{1}=\mathrm{Me}=\mathrm{R}_{2}=\mathrm{Me}, \mathrm{R}_{3}=\mathrm{H}\right)$

Figura 1 2-aminonaftaleno (1a), 2-amino-1-metil-naftaleno (1b), anilina (2a) e derivados alquilados $(2 b-m)$ (Me=metilo, diMe=dimetilo), 4-aminobifenilo (3a) e benzidina $(3 b)$.

homem a aminas primárias mono-[anilina, metil- e etil-anilinas, (2a-m)] e poliaromáticas [4-aminobifenilo (3a), por exemplo]. Estes compostos encontramse distribuídos na folha e no fumo, predominando neste último e, em particu- lar, na corrente secundária* (Cfr. tabela 1) ${ }^{9-11}$. Na origem da sua formação poderá estar a pirólise de aminoácidos e/ou proteínas e a redução de nitroarenos policíclicos na zona de queima do cigarro que é deficiente em oxigénio.

Tabela 1 Principais aminas aromáticas existentes na corrente principal e secundária do fumo do tabaco $10-11$

\begin{tabular}{lcc} 
Composto & $\begin{array}{r}\text { Corrente } \\
\text { Secundária } \\
\text { (ng/cigarro) }\end{array}$ & $\begin{array}{r}\text { Corrente } \\
\text { Principal } \\
\text { (ng/cigarro) }^{\text {a }}\end{array}$ \\
\hline Anilina & 10800 & 364 \\
\hline 2-Metilanilina & 2080 & 162 \\
\hline 3-Metilanilina & 1730 & 30,4 \\
\hline 4-Metilanilina & 1240 & 33,8 \\
\hline 2-Etilanilina + 2,6-Dimetilanilina & 2370 & 54,2 \\
\hline 2,5-Dimetilanilina & 1200 & 87,2 \\
\hline 3-Etilanilina + 2,4-Dimetilanilina & 494 & 56,7 \\
\hline 4-Etilanilina + 2,3-Dimetilanilina & 103 & 27,3 \\
\hline 1-Aminonaftaleno & 67 & 2,5 \\
\hline 2-Aminonaftaleno & 110 & 1,7 \\
\hline 2-Aminobifenilo & 132 & 3,0 \\
\hline 3-Aminobifenilo & 143 & 5,0 \\
\hline 4-Aminobifenilo & 117 & 4,6 \\
\hline 2-Metil-1-aminonaftaleno & 3,6 \\
\hline
\end{tabular}

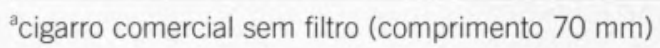

Corrente Secundária - fumo que é libertado da ponta incandescente e através do papel do cigarro durante o intervalo entre cada aspiração do fumo pelo fumador.

Corrente Principal - fumo que é aspirado pelo fumador. 
Tabela 2 Alguns exemplos dos principais adutos ADN-arilamina/arilamida detectados in vivo 4,5 .

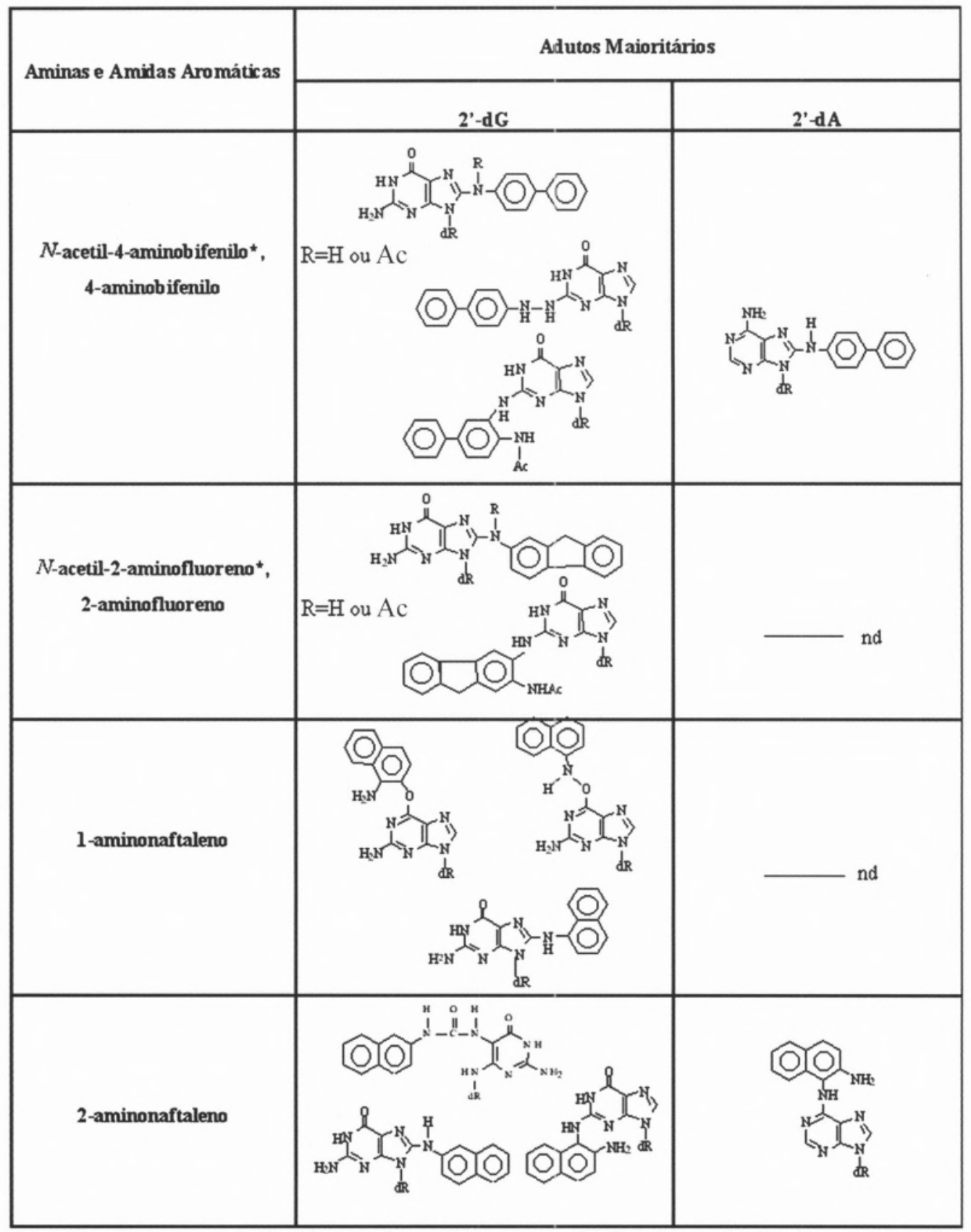

*A razão adutos não-acetilados/ $N$-acetilados é maior ou igual a 3; $\mathrm{dR}$ - desoxirribosilo; Ac - grupo acetilo; nd - não detectado.

Outros poderão, ainda, ser transferidos da folha para o fumo10.

As aminas aromáticas parecem estar associadas à etiologia do cancro em órgãos como o figado, mama, pulmões, esófago, rins e bexiga, variando o orgão afectado com o tipo de composto. 02 -aminonaftaleno (1a) e o 4-aminobifenilo (3a) cuja aç̧ão carcinogénica e mutagénica foi comprovada em roedores e humanos, são frequentemente apontadas como as principais aminas respon-

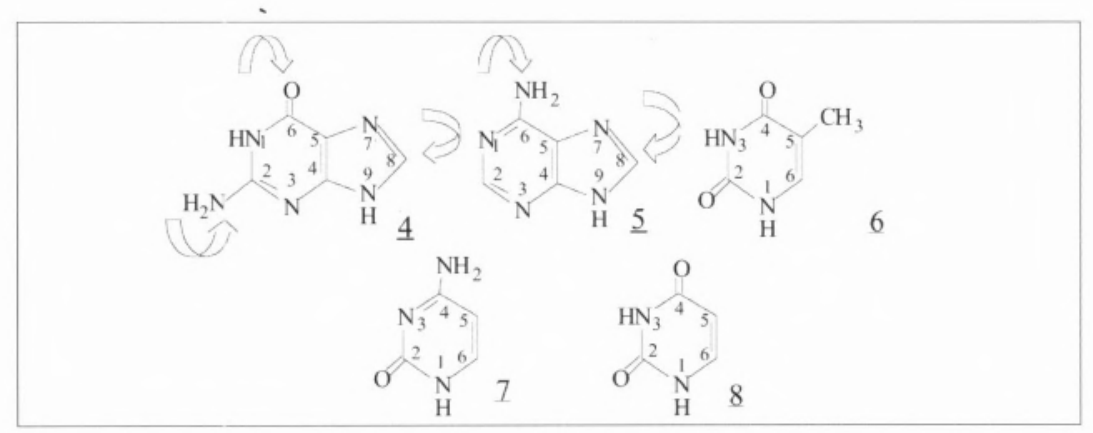

Figura 2 Bases do ADN e ARN (guanina 4, adenina 5, timina 6, citosina 7, e uracilo 8) e principais alvos de ataque de metabolitos electrófilos derivados de arilaminas. 


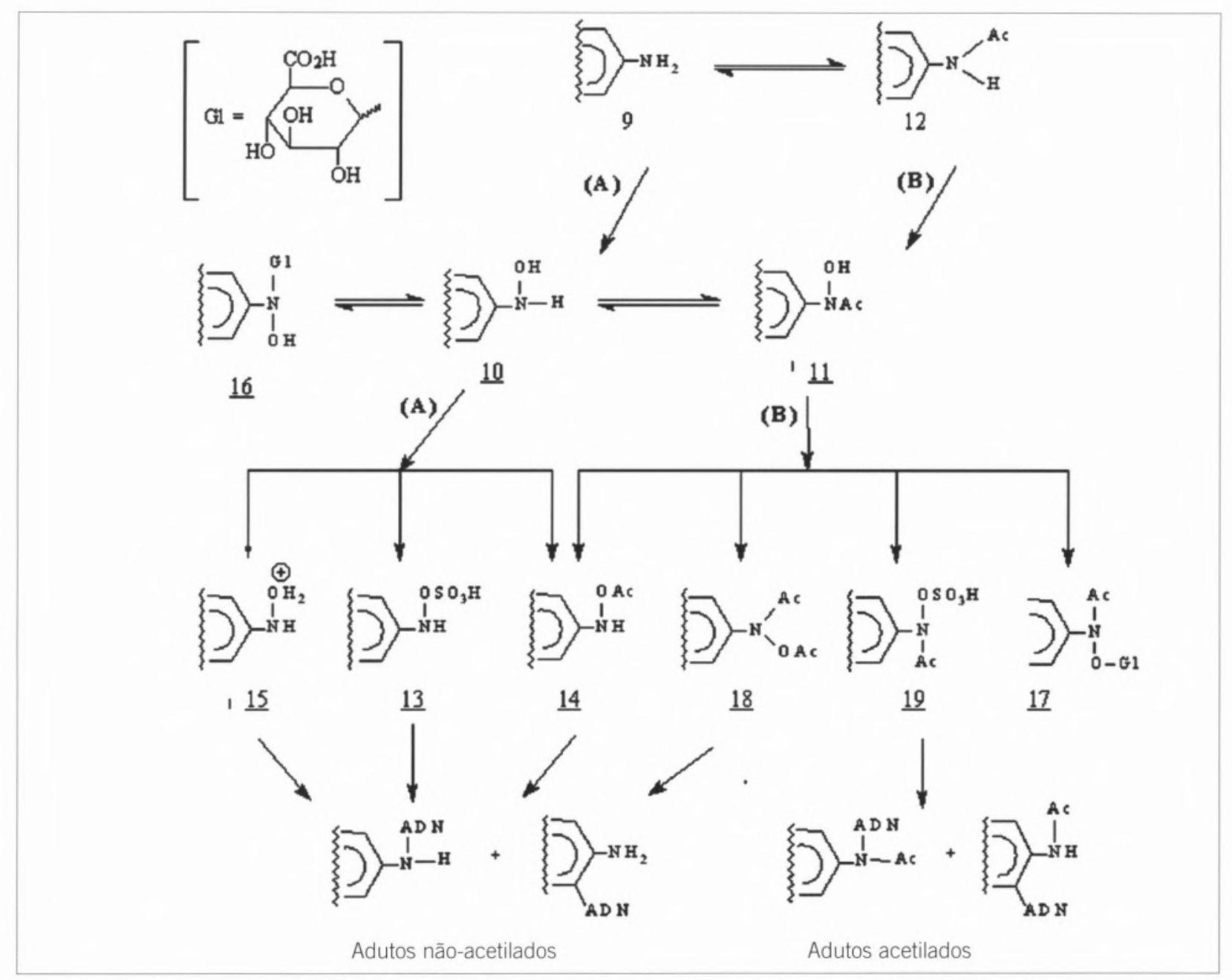

Figura 3 Vias de activação metabólica de aminas e amidas aromáticas (Ac=acetilo) ${ }^{4}$.

sáveis pela relação entre o consumo de tabaco o aumento da incidência de cancro da bexiga. De facto, as aminas aromáticas são, até hoje, a única classe de compostos químicos, presentes no fumo do tabaco, que foi inequivocamente implicada na indução do cancro da bexiga no homem ${ }^{12}$.

Os fumadores, comparativamente aos indivíduos não-fumadores, têm um risco 2 a 10 vezes superior de contrair cancro da bexiga, dependendo esse risco do consumo diário e cumulativo de cigar$\operatorname{ros}^{13}$. A corroborar com esta hipótese está o elevado número de adutos covalentes destas aminas com a hemoglobina encontrado no sangue de fumadores. Foram detectados, em média, 154 pg de 4-aminobifenilo (3a) por grama de hemoglobina no sangue de fumadores contra 28 pg por grama de hemoglobina no sangue de não-fumadores ${ }^{14}$. Os adutos com a hemoglobina são frequente- mente utilizados, em estudos epidimiológicos, como biomarcadores da exposição das populações a este tipo de compostos.

É possível, também, que para além do tabaco, o consumo de medicamentos e a dieta alimentar possam constituir outras fontes de exposição importantes às

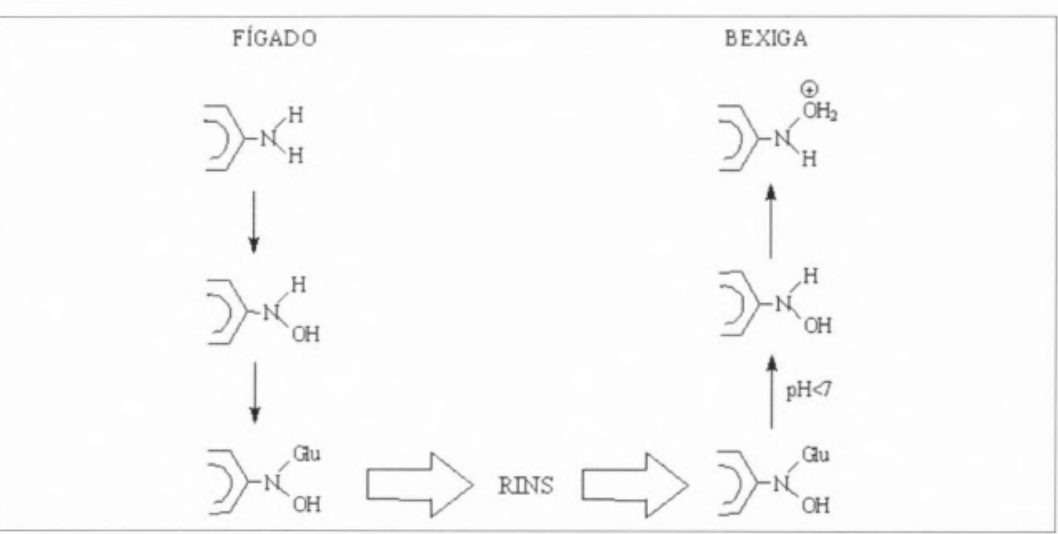

Figura 4 Função dos N-glucurónidos no transporte de N-aril-hidroxilaminas a longas distâncias ${ }^{5}$.

aminas aromáticas. Num estudo realizado com várias aminas (incluindo várias aminas poliaromáticas e 21 monoarilaminas) em populações de fumadores e de não-fumadores ${ }^{15}$, verificou-se que todas as amostras de sangue apresentavam adutos de vários daqueles compostos com a hemoglobina. A 2,6-dimetilanilina (2h) (fig 1), por exemplo, que se 


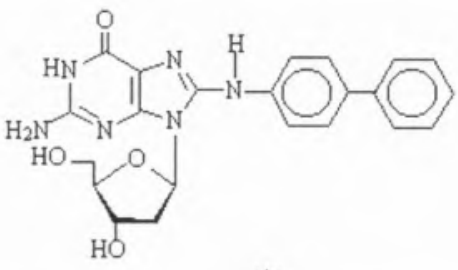

$\sin$

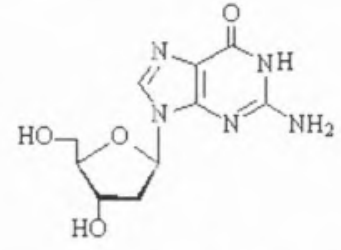

conti

Figura 5 Conformações sin e anti adoptadas, respectivamente pelo aduto $\mathrm{N}$-(desoxiguanosin-8-ii)4-aminobifenilo e pela 2 '-desoxiguanosina.

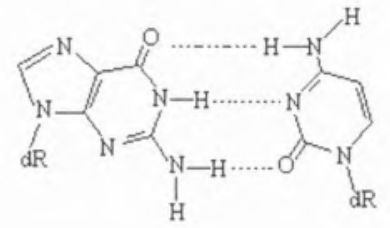

Figura 6 Emparelhamento normal de Watson-Crick (G:C) e emparelhamento errado de bases causado pela formação de um aduto no átomo de oxigénio 6 da guanina (O6-aril-G:T).

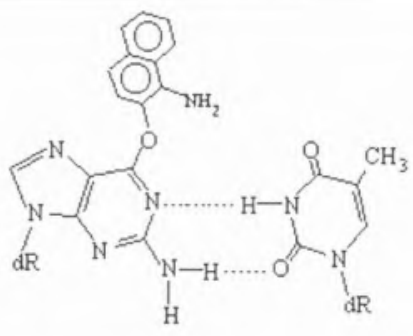

20a $\left(R_{1}=R_{2}=R_{3}=H\right)$ $\underline{20 \mathrm{~b}}\left(\mathrm{R}_{1}=\mathrm{Ac} ; \mathrm{R}_{2}=\mathrm{R}_{3}=\mathrm{H}\right)$

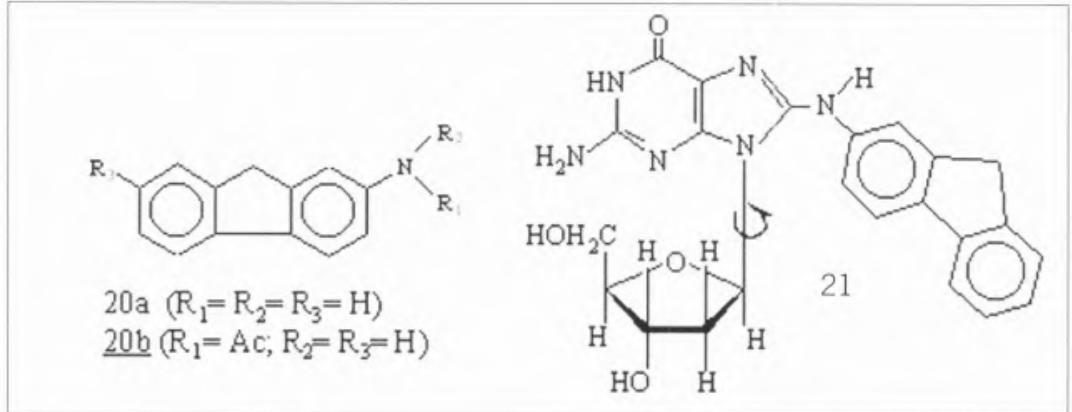

Figura 7 2- aminofluoreno (20a), 2-acetilaminofluoreno (20b, Ac=acetilo) e estrutura de adutos desacetilados do tipo 2'-dG-C8-arilamina(21), resultante da reacção entre derivados activados do 2 . acetilaminofluoreno e a 2'-desoxiguanosina.

encontra no fumo do tabaco, é também um dos principais metabolitos da lidocaína, uma substância utilizada com frequência como anestésico e na terapêutica de arritmias cardíacas 16

\section{Interacção de aminas aromáticas com o ADN: formação de adutos covalentes}

Dada a sua importância, a identidade dos adutos covalentes tem sido exaustivamente estudada quer através da realização de reacções modelo reproduzindo condições fisiológicas in vitro, quer através de estudos in vivo 4,5 . A maioria dos resultados publicados refere-se a adutos com bases do ADN e ARN, dado o seu papel crucial no armazenamento e transmissão da informação genética. Adicionalmente, ambos são considerados bons nucleófilos devido à existência de heteroátomos nas suas bases purínicas Iguanina (G) 4 e adenina (A) 5, fig. 2] e pirimidínicas [(timina ( $T$ ) 6, citosina (C) 7 e uracilo (U) 8, (fig. 2)].

Devido ao facto de uma quantidade considerável de compostos pré-cancerígenos poder ser metabolizada a mais de uma espécie electrófila e à variedade de centros nucleófilos nas macromoléculas, o número de adutos ADN-arilamina é, consequentemente, extenso e a sua estrutura variável (vidé, por exemplo, as estruturas apresentadas na tabela 2).

Tipicamente, os adutos persistentes mais abundantes encontrados após administração in vivo de aminas mono- $e$ poliaromáticas, resultam da ligação entre o átomo de azoto da amina e o carbono C8 da 2'-desoxiguanosina (Cfr. tabela 2)5,17. Apesar deste padrão de comportamento consistente, arilaminas diferentes induzem toxicidades distintas em modelos animais e as eficiências mutagénicas associadas aos respectivos adutos com a desoxiguanina em C8 variam também consuante a natureza da arilamina ${ }^{5}$.

Apesar de, como foi referido, os adutos em C8 serem os mais abundantes, foram também identificados adutos minoritários da 2'-desoxiguanosina nos átomos $\mathrm{N}^{2}$ e $\mathrm{O}^{6}$ e nos átomos $\mathrm{C} 8$ e $\mathrm{N}^{6}$ da 2 -desoxiadenosina com aminas poliaromáticas iso- e heterocíclicas 5,17-18.

\section{Activação metabólica de aminas aromáticas}

As aminas aromáticas podem ser metabolizadas às denominadas espécies "cancerígenas finais" através de percursos metabólicos alternativos. A maioria destes compostos exerce os seus efeitos biológicos na sequência de $\mathrm{N}$-oxidação enzimática a $\mathrm{N}$-aril-hidroxilaminas e/ou $\mathrm{N}$-aril-hidroxi-amidas ${ }^{4,5}$. Assim, considera-se que o primeiro passo no processo de activação metabólica de aminas aromáticas primárias (9) (fig.3) envolve a oxidação a $\mathrm{N}$-aril-hidroxilaminas (10) (percurso A) e $\mathrm{N}$-acetil- $\mathrm{N}$-aril-hidroxilaminas (11) (percurso B), catalisada pelo sistema enzimático dependente do citocromo $\mathrm{P}_{450}$. Tal como acontece com os compostos $\mathrm{N}$-hidroxilados 10 e 11 , os respectivos percursores 9 e 12 são passíveis de interconversão através da acção de $\mathrm{N}$-acetilases e $\mathrm{N}$-desacetilases. Dependendo do percurso metabólico dominante ( $\mathrm{A}$ ou $\mathrm{B}$ ), alguns indivíduos, onde a $\mathrm{N}$-acetilação ocorre mais rapidamente, contraem mais facilmente cancro de fígado, enquanto que a bexiga parece ser um alvo preferencial em indivíduos onde o percurso A é favoreci- 
do. As $N$-aril-hidroxilaminas (9) podem ser subsequentemente metabolizadas às espécies reactivas finais 13 e 14 por esterificaçāo, catalisada, respectivamente, pela acção de sulfotransferases hepáticas e da acetil-coenzima A. Uma via alternativa às duas anteriormente descritas parece ser a da obtençāo da $\mathrm{N}$-aril-hidroxilamina protonada 15 , (fig. 3) por catálise ácida não enzimática, reacção que ocorre normalmente em meios onde o pH é predominantemente ácido ( $p$. ex. na bexiga).

Alternativamente, os $\mathrm{N}$-glucorónidos (16 e 17), apesar de serem considerados metabolitos de destoxificação celular e serem relativamente estáveis a $\mathrm{pH}$ neutro, podem regenerar as $\mathrm{N}$-aril-hidroxilaminas em meios moderadamente ácidos, como por exemplo na bexiga. Assim, as $\mathrm{N}$-aril-hidroxilaminas podem posteriormente ser convertidas em espécies electrófilas do tipo 15 , por protonação e ligarem-se covalentemente ao ADN (fig.4).

\section{Conformação de Adutos ADN- -arilamina e potencial mutagénico}

A formação de um aduto covalente poderá constituir a primeira etapa do processo de iniciação de uma transformação neoplásica ${ }^{\star}$. Um princípio conceptualmente aceite é o de que um tumor se forma a partir de células que sofreram alterações permanentes e hereditárias no seu material genético. Esta hipótese que terá tido a sua origem na observaçāo de que as células tumorais apresentam mecanismos de replicação alterados, é reforçada pelo facto da maioria dos tumores induzidos quimicamente serem monoclonais ${ }^{4}$. Assim, e em linhas gerais, se durante o processo de replicação do $A D N$, a $A D N$-polimerase encontrar um aduto e o erro não for reparado, podem observar-se mutações pontuais por substituição, adição ou supressão de uma base. Dependendo do tipo e/ou do local de ocorrência dessas alterações (proto-oncogene), a mutação poderá ser silenciosa ou dar início a um processo cancerígeno.
Alguns estudos têm sugerido que a eficiência mutagénica ( $n .^{\circ}$ de mutações / aduto) e o tipo de mutações induzidas pela presença de adutos covalentes no ADN estão intimamente relacionados com factores estruturais, isto é, com o tipo e estrutura destes adutos quando inseridos na dupla hélice do ADN19,20.

Entre os factores estruturais mais relevantes encontrados entre os adutos derivados de aminas aromáticas constam o tamanho do sistema aromático (número de anéis fusionados) e a presença de substituintes alquilo (número e posição dos mesmos). Assim, esta variedade estrutural poderá ter como consequência a possibilidade destes adutos adoptarem uma conformação do tipo sin em torno da ligaçāo glicosílica, em oposição à conformação anti adoptada normalmente pela $2^{\prime}$-desoxiguanosina quando incorporada no ADN (fig. 5).

Um dos erros provocados pela alteração da conformação das bases é a perda do emparelhamento de Watson-Crick (fig.6) entre bases complementares na dupla hélice do ADN. Convém relembrar que somente a planaridade e a forma tautomérica correcta permitirāo, respectivamente, um empilhamento e um emparelhamento correcto das bases.

As distorções locais observadas na dupla hélice do ADN poderão estar também relacionadas com o número e tipo de confórmeros que são energeticamente acessiveis a cada um dos adutos formados. Com dois compostos pertencentes à classe das aminas aromáticas, o 4-aminobifenilo (3a), (fig. 1) e o 2-acetilaminofluoreno (20b, fig. 7 ), verificouse, por exemplo, que apesar de ambos originarem adutos estruturalmente idênticos no fígado de ratos (adutos desacetilados do tipo 2'-dG-C8-arilamina, 21, fig.7), o primeiro é cerca de duas vezes mais eficiente na indução de tumores hepáticos ${ }^{21,22}$. Os estudos de ressonância magnética nuclear efectuados com oligonucleótidos modificados com 02 aminofluoreno (20a) e com o 4-aminobifenilo (3a) $)^{23,24}$, (fig. 1), revelaram que os adutos derivados daquelas aminas apresentavam predominantemente duas conformações, numa das quais a 2'-dG modificada se encontrava na conformação anti. Na outra, a 2'-dG apresentava uma conformação do tipo sin, o que fazia com que o fragmento aromático do aduto se intercalasse entre bases adjacentes de uma das hélices do ADN. Dado que a percentagem de confórmeros sin era substancialmente superior para o aduto derivado do 2-aminofluoreno comparativamente ao do 4-aminobifenilo, foi sugerido que esta conformação poderia estar na origem do acréscimo observado nas propriedades mutagénicas do primeiro composto.

Também a presença e posição de substituintes alquilo no resíduo aromático das aminas parecem influenciar a sua eficiência mutagénica. As aminas aromáticas metiladas em posição orto relativamente ao grupo $-\mathrm{NH}_{2}$ são, em geral, mais mutagénicas que as suas congéneres não metiladas. Como exemplo ilustrativo cita-se, entre muitos outros, o caso do 2-amino-1-metil-naftaleno (1b), (fig. 1) que é 3 vezes mais mutagénico em bactérias Salmonella typhymurium TA100 que o seu homólogo não-metilado - o 2-aminonaftaleno (1a)24. Comportamentos semelhantes foram também observados com derivados $\mathrm{N}$-hidroxilados de aminas monoaromáticas alquiladas em várias posiçōes do anel aromático, onde a introdução de um grupo alquilo em posição orto induzia, comparativamente aos restantes isómeros, maiores respostas mutagénicas $^{19}$.

Tem-se verificado, também, que o tipo de mutações induzidas por esta classe de compostos depende do tipo de aduto. Uma boa percentagem das mutações associadas a aminas que promovem, fundamentalmente, a formação de adutos derivados da 2'-desoxiguanosina em C8 e $N^{2}$, originam, com maior frequência, substituições de uma base purínica por uma pirimidínica $(\mathrm{G} \rightarrow \mathrm{T}$ e/ou $\mathrm{G} \rightarrow \mathrm{C}$ ). Este tipo de mutação foi encontrado no ADN de células de tumores extraidos de ratos aos quais foi administrado 2 -aminonaftaleno (3a) e benzidina (3b).

\footnotetext{
- Transformação neoplásica - Crescimento autónomo de tecido num organismo sem função fisiológica aparente (tumor).
} 


\section{Considerações Finais}

Os estudos realizados no âmbito da carcinogénese química têm reforçado a ideia de que a exposição crónica a certas classes de compostos possa ser a causa primária da iniciação e desenvolvimento de um processo cancerígeno. Adicionalmente, e como resultado dos numerosos ensaios realizados, in vitro e in vivo, tem-se verificado que os compostos cancerigenos são, na sua maioria, mutagénicos; que as propriedades mutagénicas e carcinogénicas de muitos compostos dependem da sua conversão in vivo a derivados com características electrófilas capazes de reagir com os centros nucleófilos das macromoléculas biológicas; que a extensão de modificação química do ADN é, em muitos casos, correlacionável com as respostas mutagénicas e carcinogénicas observadas e que 0 aparecimento de lesões químicas em determinadas posiçōes do ADN é responsável pela activação de sequências específicas, denominadas por proto-oncogenes.

Convém salientar, que paralelamente à exposição a electrófilos exógenos, o genoma humano e dos mamíferos, de um modo geral, é susceptivel de ataque por substâncias reactivas endógenas 26,27 que não necessitam sofrer activação metabólica. Alguns tipos de danos endógenos observados no ADN resultam de condiçōes de stress oxidativo das suas bases ou da formação de adutos derivados de produtos resultantes da peroxidação lipídica.

Para além dos testes de genotoxicidade (que utilizam uma variedade de organismos como bactérias, fungos e linhas celulares de mamíferos), a contribuição das aminas aromáticas para a etiologia do cancro humano envolve, necessariamente, a quantificação e identificação estrutural dos adutos do ADN detectados em amostras de tecidos de animais e humanos. Os métodos de detecção e análise de adutos do ADN [como por exemplo, a marcação isotópica com carbono-14 ou trítio, a pós-marcação com fósforo-32, os imunoensaios (RIA e ELISA)* e a espectrometria de massa], associados à síntese de padrōes de nucleótidos e nucleósidos modificados, têm contribuído decisivamente para uma maior compreensão da base molecular da carcinogénese química.

\section{Agradecimentos}

A autora agradece à Professora Doutora M. Matilde Marques pelo incentivo, apoio e meios de trabalho concedidos no seu grupo de investigação no Centro de Química Estrutural do IST.

\section{Bibliografia}

1. Miller, E.C. (1978) Cancer Res. 38, 1479 1496.

2. Hathway, D.E. (1986) em Mechanisms of Chemical Carcinogenesis, 1. ${ }^{a}$ Ed. (Butleworth \& Co. Ltd. Ed.), cap. 2, 14-46.

3. Guengerich, F.P (2001) Mut. Res. 488 , 195-209.

4. Beland, F.A., Poirier, M.C. (1989) em The Pathobiology of Neoplasia, ( Sirica, A.E., Ed.) cap. 3, 57-80, Plenum Publishing Corp., New York.

5. Beland, F.A., Kadlubar F.F. (1990) em Handbook of Experimental Pharmacology Carcinogenesis and Mutagenesis (Cooper, C.S. e Grover, P.L., Ed.) Vol. 94/1 , 267-325, Springer-Verlag, Heidelberg.

6. Rehn, L. (1895) Arch. Klin. Chir. 50, 588600 .

7. Case, R.A.M., Hosker, M.E. (1954) Br. J. Prevent. Soc. Med. 8, 39-50.

8. Hueper, W.C., Wiley, F.H., Wolfe, H.D. (1938) J. Ind. Hug. Toxicol., 20, 46-84.

9. Stedman, R.L. (1968) Chem. Rev. 68 , 153-207.

10. Schmeltz, I., Hoffmann, D. (1977) Chem. Rev. 77, 295-311.
11. Patrianakos, C., Hoffmann, D. (1979) J. of Anal. Toxicol 3, 150-154.

12. Vineis, P., Caparoso, N. (1995) Env. Health Perspectives 103, 156-160.

13. Bartsch H., Caporaso, N., Coda, M., Kadlubar, F., Malaveille, C., Skipper, P., Talaska, G., Tannenbaum, S.T., Vineis, P. (1990) J. Nat. Cancer Inst. 82, 1826-1831.

14. Bryant, M.S., Skipper, P.L., Tannenbaum, S.R., Maclure, M.(1987) Cancer Res. 46, 602-608,

15. Sabbioni, G., Beyerbach, A. (1995) J. Chromatogr. B. 667, 75-83.

16. Narang, P. K., Crouthamel, W. G., Carliner, N. H., Fisher, M. L. (1978) Clin. Pharmacol. Ther. 24, 654-662.

17. Marques, M.M., Beland, F.A. (1994) em DNA Adducts: Identification and Biological Significance. IARC Sci. (Hemminki, K., Dipple, A., Shuker, D.E.G., Kadlubar, F.F., Segerbäck, Bartsch, H., Ed.), Vol. 125, 453456, International Agency for Research on Cancer, Lyon.

18. Turesky, R.J., Lang, N.P., Butler, M.A., Teitel, C.H., Kadlubar, F.F. (1991) Carcinogenesis 12, 1839-1845.

19. Beland, F.A., Melchior Jr., W.B., Mourato, L.L.G., Santos, M.A., Marques, M.M. (1997) Mutation Res. 376, 13-19.

20. Seo, K.Y., Jelinsky, S.A., Loechler, E.L., (2000) Mut. Res. 463(3), 215-246.

21. Poirier, M.C., Fullerton, N.F., Kinouchi, T., Smith, B.A., Beland, F.A.(1991) Carcinogenesis 12, 895-900.

22. Poirier, M.C., Fullerton, N.F., Smith, B.A., Beland, F.A.(1995) Carcinogenesis 16. 2917-2921.

23. Cho, B.P., Beland, F.A., Marques, M.M.(1992) Biochemistry 31, 9587-9602.

24. Cho, B.P., Beland, F.A., Marques, M.M. (1994) Biochemistry 33, 1373-1384.

25. El-Bayoumy, K., La Voie, E.J., TulleyFreiler, L., Hecht, S.S. (1981) Mut. Res. 90 , 345-354.

26. Cavalieri, E., Frenkel, K., Liehr, J.G., Rogan, E., Roy, D. (2000) J. Natl. Cancer Inst. Monogr., 27, 75-93.

27. Phillips, D.H., Farmer, P.B., Beland, F.A., Nath, R.G., Poirier, M.C., Reddy, M.V., Turteltaub, K.W. (2000) Environ. and Molecular Mutagenesis 35, 222-233. 